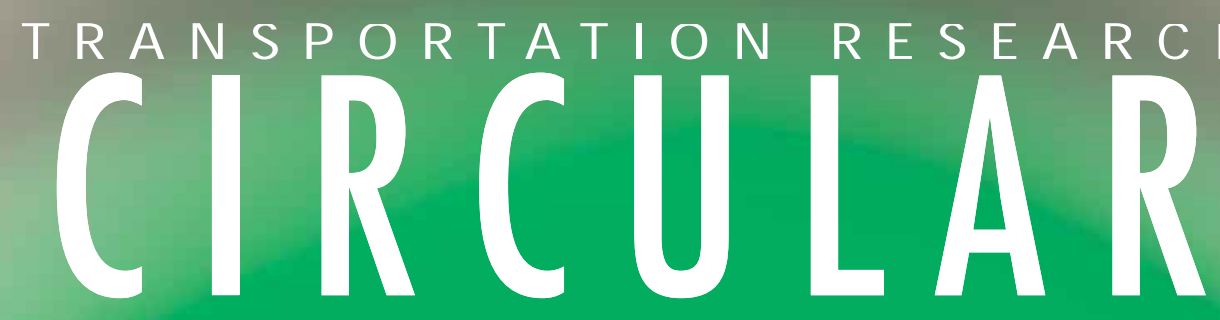

Number E-C089

January 2006

\title{
Critical Issues in Aviation and the Environment 2005
}




\section{TRANSPORTATION RESEARCH BOARD}

\section{EXECUTIVE COMMITTEE OFFICERS}

Chair: John R. Njord, Executive Director, Utah Department of Transportation, Salt Lake City

Vice Chair: Michael D. Meyer, Professor, School of Civil and Environmental Engineering, Georgia Institute of Technology, Atlanta

Division Chair for NRC Oversight: C. Michael Walton, Ernest H. Cockrell Centennial Chair in Engineering, University of Texas, Austin

Executive Director: Robert E. Skinner, Jr., Transportation Research Board

\section{TRANSPORTATION RESEARCH BOARD}

2005 TECHNICAL ACTIVITIES COUNCIL

Chair: Neil J. Pedersen, State Highway Administrator, Maryland State Highway Administration, Baltimore

Technical Activities Director: Mark R. Norman, Transportation Research Board

Christopher P. L. Barkan, Associate Professor and Director, Railroad Engineering, University of Illinois at Urbana-Champaign, Rail Group Chair

Christina S. Casgar, Office of the Secretary of Transportation, Office of Intermodalism, Washington, D.C., Freight Systems Group Chair

Larry L. Daggett, Vice President/Engineer, Waterway Simulation Technology, Inc., Vicksburg, Mississippi, Marine Group Chair

Brelend C. Gowan, Deputy Chief Counsel, California Department of Transportation, Sacramento, Legal Resources Group Chair

Robert C. Johns, Director, Center for Transportation Studies, University of Minnesota, Minneapolis, Policy and Organization Group Chair

Patricia V. McLaughlin, Principal, Moore Iacofano Golstman, Inc., Pasadena, California, Public Transportation Group Chair

Marcy S. Schwartz, Senior Vice President, CH2M HILL, Portland, Oregon, Planning and Environment Group Chair

Agam N. Sinha, Vice President, MITRE Corporation, McLean, Virginia, Aviation Group Chair

Leland D. Smithson, AASHTO SICOP Coordinator, Iowa Department of Transportation, Ames, Operations and Maintenance Group Chair

L. David Suits, Albany, New York, Design and Construction Group Chair

Barry M. Sweedler, Partner, Safety \& Policy Analysis International, Lafayette, California, System Users Group Chair 


\section{Critical Issues in Aviation and the Environment 2005}

Transportation Research Board

Environmental Impacts of Aviation Committee

January 2006

Transportation Research Board 500 Fifth Street, NW

Washington, DC 20001

www.TRB.org 


\title{
TRANSPORTATION RESEARCH CIRCULAR E-C089
}

ISSN 0097-8515

The Transportation Research Board is a division of the National Research Council, which serves as an independent adviser to the federal government on scientific and technical questions of national importance. The National Research Council, jointly administered by the National Academy of Sciences, the National Academy of Engineering, and the Institute of Medicine, brings the resources of the entire scientific and technical communities to bear on national problems through its volunteer advisory committees.

The Transportation Research Board is distributing this Circular to make the information contained herein available for use by individual practitioners in state and local transportation agencies, researchers in academic institutions, and other members of the transportation research community. The information in this Circular was taken directly from the submission of the authors. This document is not a report of the National Research Council or of the National Academy of Sciences.

\author{
Aviation Group \\ Agam N. Sinha, Chair
}

Environmental Impacts of Aviation Committee

Katherine B. Andrus, Chair

\author{
Mary Ellen Eagan \\ Christopher D. Grant \\ Peter J. Gray-Mullen \\ Wayne W. Kober \\ John A. Lengel, Jr. \\ Kristi McKenney \\ Michael T. McNerney
}

\author{
Burr Stewart, Vice Chair \\ Richard L. Altman \\ Richard Burke \\ teven Davis-Mendelow \\ Julie Ann Draper
}

\author{
Anthony D. Perl \\ Ian A. Redhead \\ Claudio H. Ternieden \\ Mary Lee Vigilante \\ Catherine W. Wetherell \\ Chowen Chou Wey \\ Daniel T. Wormhoudt \\ Darcy Zarubiak
}

Christine L. Gerencher, TRB Staff Representative

Nancy Doten, Senior Program Assistant

\author{
Transportation Research Board \\ 500 Fifth Street, NW \\ Washington, DC 20001 \\ www.TRB.org
}

Ann E. Petty, Production Editor; Jennifer Correro, Proofreader and Layout 


\section{Contents}

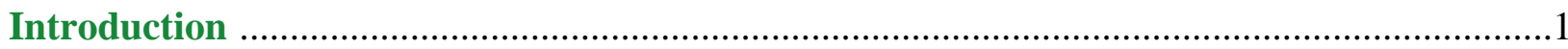

Daniel T. Wormhoudt and Katherine B. Andrus

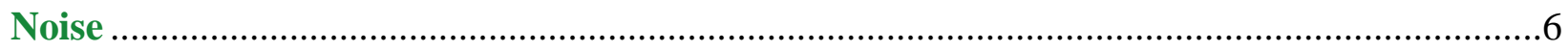

Mary Ellen Eagan

Air Quality ....................................................................................................................... 11

Julie Ann Draper, Kristi McKenney, Mary Lee Vigilante, Chowen Chou Wey

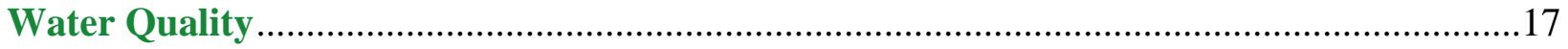

Richard S. Davis and Claudio H. Ternieden

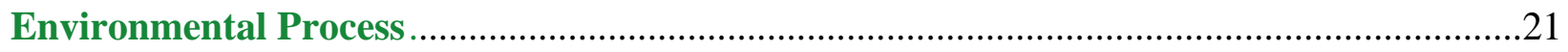

John E. Putnam

Tools

Julie Ann Draper

Technology Deployment

Richard L. Altman 


\title{
Introduction
}

\author{
DANIEL T. WORMHOUDT \\ Environmental Science Associates
}

KATHERINe B. ANDrus

Air Transport Association of America, Inc.

\section{BACKGROUND}

From the beginnings of powered flight more than a century ago, the potential impact of aviation on the natural and human environment has been recognized, if often poorly understood. The development of airfields and airports in this country requires terrain that is level and free of natural obstructions in the vicinity, and these facilities must be easily accessible to cities and towns, which in turn are situated often near rivers, lakes, and oceans. Because of these factors, airports have tended to develop on large, flat sites in proximity to major bodies of water-sites that typically support diverse and complex natural systems vulnerable to disturbance. Development of airports also has affected the social environment and vice versa. Airports originally constructed far from town often become embedded within the metropolitan areas that have grown up around them, bringing areas where large numbers of people live and work much closer to the airport fence than the planners of either the airports or the cities anticipated. Moreover, aviation impacts are not limited to airport environs. As awareness of the global environment evolves, more attention is being paid to the potential environmental impact of aircraft operating at altitude as well as near airports. Today, while aviation traffic has become an important and growing mode of transport, the environment has become increasingly stressed from a variety of sources, population continues to expand, and the connections between these elements have become increasingly complex and difficult to manage efficiently and equitably. Research on ways to assess and ameliorate these conditions is under way and promises substantial benefits. A future in which aviation exists in harmony with the natural and human environment is possible but cannot occur without better knowledge and understanding of existing and future environmental impacts and the opportunities for mitigating or avoiding them. This report summarizes progress that we are making toward that future.

\section{OVERVIEW}

The Transportation Research Board (TRB) Environmental Impacts of Aviation Committee (AV030) issued its first annual summary of critical issues in aviation and the environment in the United States in 2004 (TRB, 2004). This report updates that summary with the goal of identifying priority research that can yield potential benefits during a period that spans the next several years to several decades. The value of the summary is intended to be its crossdisciplinary review of topics of interest to airports and other elements of the civil aviation community, with the focus on the state of science rather than on policy. The summary comprises six sections: three that address the major environmental media affected by aviation activities (noise, air quality, and water quality) and three that address key processes that link aviation and 
the environment (analytical tools, environmental review processes, and technology deployment). Each section is divided into subsections that

- Define the critical issues in the media or process area;

- Discuss the current state of practice, research, and policy;

- Define a vision of future capabilities that would address the critical issues; and

- Identify specific research needs to help achieve the vision.

Each section focuses on research conducted in the United States, although international activities are discussed where U.S. public or private entities are closely involved. A variety of published and unpublished material, public information, and individual contributions were collected to prepare this paper, as noted in the references at the end of each topic area. Figure 1 illustrates the six sections and their component research areas considered in this review.

Because of constraints on time and effort, the critical issues portions of each section do not claim to address all potentially critical issues in a given field. For example, the paper does not fully address climate change, which is a critical emerging environmental issue to which the aviation community must devote more research to understand more clearly the aviationenvironment relationship. Neither does it comprehensively address land use development near airports, which represents a major constraint on future aviation activity and for which effective controls need to be developed. Sustainable development, threatened and endangered species, air and drinking water quality inside aircraft and airports, and other topics also are not addressed but may be added in future papers. The critical issues listed here are varied and have evolved over time and will continue to do so. For example, while aircraft noise impacts were once preeminent among the operational environmental issues associated with aviation, air quality concerns have now achieved nearly equivalent status. Water quality issues now seem likely to assume the same sort of importance that special status species and wetlands impacts have long held.

The current state portion of each of the papers addresses efforts now under way in the broad community of professionals concerned with aviation and the environment to advance the resolution of the issues. To this end, TRB maintains a number of committees and task forces that focus on specific environmental topics (e.g., noise and air quality), as well as committees concerned with various aspects of aviation. The Environmental Impacts of Aviation Committee coordinates with all of the other committees in the planning of meetings, annual meeting sessions, paper reviews, and similar matters. The current state portions of the paper help to further one of the goals of the Environmental Impacts of Aviation Committee - to integrate the work of other TRB committees, along with research produced in the various sectors of the aviation community, into a summary document focused on research addressing the environmental impacts of aviation.

The "Future Vision" portions of the papers reflect current public policy and are intended to be descriptive rather than prescriptive. Much input is derived from Vision 100, the FAA reauthorization bill enacted by Congress in December 2003. Vision 100 included extensive environmental provisions designed to streamline environmental review processes and to mitigate aviation's environmental impacts with a number of noise and air quality initiatives, thus directly addressing what are typically the most significant aviation environmental impacts. For example, Vision 100 established a new voluntary program to reduce airport ground emissions at commercial service airports in air quality nonattainment and maintenance areas and allows more 


\section{Aviation Environmental Research Agenda Overview Map}

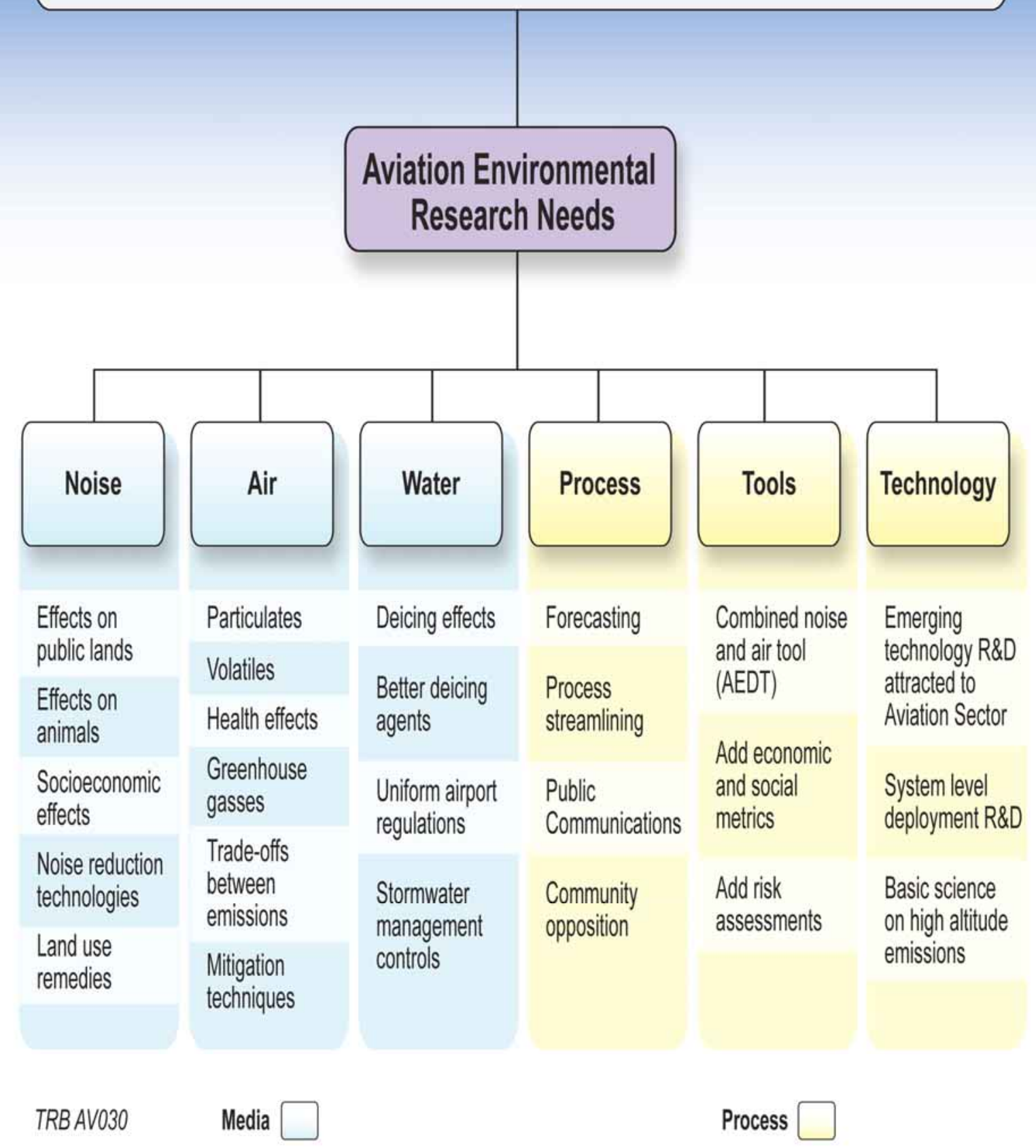

FIGURE 1 
flexible use of the airport improvement program (AIP) to fund this program. The noise set-aside has been funded at a higher level to support emission projects and to fund grants to state and local governments to enhance the compatibility of land uses adjacent to large- and medium-sized airports. Vision 100 also added flexibility in the use of AIP grants to fund the mitigation of noise impacts of airport expansion. Vision 100 provided for streamlined environmental review processes for airport capacity projects, aviation safety projects, and aviation security projects. These public policy goals may be continued or revised in the next FAA reauthorization, which will be taken up by Congress in 2006-2007. In addition, Congress has recently directed the administration to develop a national aeronautics policy in 2006 to provide policy direction concerning the government's role in the civil aviation industry and particularly in civil aviation research. While the scope of the national aeronautics policy will go beyond the issues identified in this paper, it likely will address some of the environmental research described in the following sections.

"Research Needs" set forth in the papers include initiatives that may be undertaken by the newly authorized and funded Airports Cooperative Research Program (ACRP). The purpose of ACRP, which is based in part on the cooperative research programs in transit and highways, is to fund research projects identified by airports as having high priority, clearly defined objectives, and immediate practical applications. Among the types of research projects enumerated in the National Research Council report recommending establishment of the ACRP are several that are environmental in nature, and proposals addressing environmental topics are among those eligible for funding. The paper's sections draw from these recommendations and, in turn, may provide useful inputs into that program's research decisions.

\section{ACKNOWLEDGMENTS}

This summary represents the viewpoints of the authors and reviewers of the individual papers. Sections were reviewed by a number of the members and friends of the Environmental Impacts of Aviation Committee, including

- Richard Burke (lead reviewer), Kennedy/Jenks Consultants;

- Katherine B. Andrus, Air Transport Association;

- Carl Burleson, FAA Office of Environment and Energy;

- Lourdes Maurice, Federal Aviation Administration;

- Anthony D. Perl, University of Calgary, Canada; and

- Darcy Zarubiak, Leigh Fisher Associates.

The contribution of the Airports Council International-North America section's Air Quality Subcomittee paper concerning hazardous air pollutants, led by Pamela Vanderbilt of $\mathrm{CH} 2 \mathrm{M}$ HILL, is also acknowledged.

The TRB Environmental Impacts of Aviation Committee plans to update this summary annually. Comments on the summary or on individual papers, or on both, are welcomed by the committee and should be addressed to the chair of the TRB Environmental Impacts of Aviation Committee (AV030): Katherine B. Andrus, assistant general counsel, Air Transport Association, 
1301 Pennsylvania Avenue, N.W., Suite 1100, Washington, D.C. 20004-1707; 202-626-4000; Fax: 202-626-4139; e-mail: kandrus@ airlines.org.

\section{REFERENCES}

Transportation Research Circular E-C069: Critical Issues in Aviation and the Environment. Transportation Research Board, National Research Council, Washington, D.C., 2004. 


\author{
Noise \\ MARY ElLen EAgan \\ Harris Miller Miller and Hanson
}

\title{
CRITICAL ISSUES
}

Aircraft noise historically has been one of the major constraints to increasing civil aviation capacity. Despite the facts that community exposure to aircraft noise has decreased markedly over the past several decades and that the National Aeronautics and Space Administration (NASA) and the European Community have ambitious technology goals for the future, community expectations of continued decreases in noise levels may not reflect the reality of the extended time frame required for development and adoption of advanced technology for the next generation of quieter aircraft.

\section{CURRENT STATE}

Several efforts are under way to address the problem of aircraft noise by designing aircraft that generate less noise and to improve the compatibility of lands near airports with their respective noise exposure. Other research efforts have focused on operating aircraft to reduce noise impacts and on planning airports and surrounding communities to avoid exposing sensitive land uses like homes and schools to aircraft noise. Aviation noise research in the United States is conducted in a number of different institutional settings, including federal and state governments, universities, and private consulting firms. Federal agencies coordinate research priorities and findings through the Federal Interagency Committee on Aviation Noise (FICAN, http://www.fican.org ). FICAN members include the U.S. Department of Transportation, U.S. Department of Defense (DoD), Environmental Protection Agency (EPA), NASA, U. S. Department of Housing and Urban Development (HUD), and U.S. Department of the Interior. Research undertaken by these agencies includes the following:

- NASA's Quiet Aircraft Technology Program was designed to conduct research on ways to remove noise as a constraint on air transportation. Its vision is to contain noise within the airport boundary. NASA has identified a 10-year goal of containing airport noise measured in terms of a day-night noise level (DNL) of $65 \mathrm{~dB}$ or greater within the airport boundary and a 25year goal of containing DNL of $55 \mathrm{~dB}$ or greater within the airport boundary. However, although NASA has achieved great progress, the future of noise technology research at NASA is uncertain and is tied to the continuing debate on the role of aeronautics in that agency.

- DoD coordinates research across the services through its Unified Airborne Noise Program. The goals of the DoD working group include $(a)$ development of a strategic environmental noise research plan coordinated through the armed services and $(b)$ establishment of a defense environmental noise working group to staff and prioritize the issues. The program will address requirements and funding priorities across the mainstream of DoD airborne noise issues including models, data acquisition, and research and development. 
- DoD has developed a number of tools in support of the Air Installation Compatible Use Zone Program and National Environmental Policy Act of 1969 (NEPA) documentation. NOISEMAP is used to model noise exposures in the vicinity of a military air base due to aircraft flights, maintenance, and ground run-up activities. The Rotorcraft Noise Model is used to calculate noise exposure specifically from helicopters and tilt wing aircraft such as the V-22 Osprey. Other models include the Military Operating Area and Range Noise Model and ROUTEMAP to predict noise levels from aircraft flights on military training routes, and other supplemental tools. Future development plans include migration from energy-based models such as NOISEMAP and supporting suites of tools to time-based simulation models, which use noise hemispheres as the basis for development of three-dimensional noise footprints.

- DoD has been the primary agency funding research on aviation noise effects on animals, including recent studies on Mexican spotted owls, red-cockaded woodpeckers, marine mammals, and other aquatic animals. There has been some work to develop models for predicting aviation noise as it propagates through the air-water transition zone and under water.

- FAA and NASA, in collaboration with Transport Canada, are sponsoring an Air Transportation Center of Excellence for Aircraft Noise and Aviation Emissions Mitigation, called the Partnership for Air Transportation Noise and Emissions Reduction (PARTNER). Established in 2003, PARTNER has developed a strategic plan that includes noise, emissions, and interdependencies elements. The center's accomplishments over the past 2 years include

- Report to Congress, Aviation and the Environment: A National Vision Statement, Framework for Goals and Recommended Actions;

- Methodology for jointly assessing health and welfare risks of noise, climate, and local air quality;

- Major research campaigns at three active airports, including a congressionally mandated study of low-frequency noise campaign;

- Demonstration of the feasibility of using the continuous descent approach noise mitigation procedure for multiple aircraft at Louisville Airport, Kentucky. This research is transitioning into operation at Louisville; and

- Longer-term efforts to develop models to assess the socioeconomic effects of noise and noise mitigation, noise abatement flight procedures at higher density airports, compatible land use management, and airport operational controls.

- FAA has undertaken a survey to identify and evaluate innovative programs that employ land use controls to address community noise exposure. Certain states (e.g., Florida and California) also have adopted land use compatibility evaluation and planning processes for airports and their environs.

- FAA has initiated development of a new toolset that integrates engine and aircraft design with aircraft operations to examine environmental performance and technology development and cost-benefit of actions to mitigate environmental impact. TRB assisted the FAA in the development of the model by facilitating workshops and soliciting input from the aviation user, operations, manufacturing, and research communities on FAA's plan. On the basis of this input, the FAA has launched the necessary research to develop the toolset and has made substantive progress on a broad range of technical work items.

- FAA, in cooperation with the National Park Service (NPS), has the lead role in developing Air Tour Management Plans for national parks that are or are anticipated to become air tour destinations. The goal of these plans is to minimize the effects of aircraft noise in sensitive parklands. 
- FAA has been working with the United Nations International Civil Aviation Organization (ICAO) on the development of noise standards for the next generation of civil aircraft. The Stage 4 noise standard adopted by ICAO requires newly manufactured aircraft to be at least $10 \mathrm{~dB}$ quieter than Stage 3 aircraft. The Stage 4 standard, which took effect on January 1, 2006, also includes provisions for recertifying existing aircraft to meet the more stringent standard.

- The Department of the Interior conducts research on the effects of aircraft overflights, watercraft, snow machines, ground transportation vehicles, and other sources of human-produced sounds on units of the National Park system. The lead agency for the department is the NPS. As part of its efforts, the NPS has issued director's Order 47 to articulate its policies that require the protection, maintenance, or restoration of the natural soundscape resource in the national parks. This order directs park superintendents to use the NPS planning process to ensure the preservation or restoration of natural soundscapes.

- Currently, there is no noise research program at EPA or HUD.

- A number of nongovernmental groups concerned with aviation have research programs or research agendas, including the following:

- The TRB Transportation-Related Noise and Vibration Committee (ADC40) prepared a list of research needs as part of the TRB Environmental Research Needs Conference in March 2002. The committee's research priorities include a cost-benefit analysis of transportation noise, development of a methodology for quantifying transportation noise exposure in the United States, an aircraft noise health effects study, aircraft community noise impact below $65 \mathrm{~dB}$ DNL, best practices for sound insulation around airports, technical tools to support land use compatibility planning, a synthesis of noise effects on wildlife and development of impact assessment guidelines, a study of community response to non-aircraft transportation noise, and research on helicopter noise impacts to the community.

- SAE's Aviation Noise Committee (SAE-A21) is tasked with developing standards and practices in the area of interior and exterior noise associated with aircraft and their environments. Research supporting this effort currently includes monitoring noise from aircraft operations in the vicinity of airports and application of pure-tone atmospheric absorption to onethird octave-band data.

- The United States launched the Next Generation Air Transportation System (NGATS) effort, a multiagency (DOT's Office of the Secretary, FAA, NASA, DoD, Department of Commerce, Department of Homeland Security, and the Office of Science and Technology Policy) integrated effort to ensure that the future air transportation system meets air transportation security, mobility, and capacity needs while reducing environmental impacts. The NGATS includes an Environmental Integrated Product Team (EIPT), which is addressing a number of strategies to reduce aviation's noise impact in absolute terms.

\section{FUTURE VISION}

We need to develop advanced technologies and operational procedures that will further reduce aircraft noise and noise exposure. Since this effort will require time to develop and deploy, we need to understand better the relationship between aviation noise and community reaction, and we need to find ways to make aviation more compatible with nearby communities. 


\section{RESEARCH NEEDS}

Research priorities for aviation noise fall into the following categories:

- Continue to improve long- and short-term noise reduction technologies. Ongoing research in source noise reduction is focused on design elements as well as operational procedures. Long-term needs include new technologies to address engine, airframe, and structural noise. Shorter-term research needs include optimization of low-noise operational procedures (e.g., navigational-aided departures and approaches, noise abatement departure procedures); demonstrations and evaluations of low-noise operational procedures and their impact on capacity; assessment of the effectiveness of the aircraft noise certification demonstration procedures in promoting low-noise designs for modern aircraft; and investigation of new procedures taking noise and emissions reduction and associated capacity benefits from advances in airborne and ground technologies for communication, navigation, and surveillance.

- Examine the socioeconomic effects of noise on people and quality of life. A number of issues remain to be resolved through research, including examination of the explicit and implicit costs of aircraft noise; evaluations of the adequacy of the current noise metrics used in the assessment of noise impacts and development and application of supplemental noise metrics; examination of the relationship between human health and noise, including sleep and sleep disturbance effects, differing impacts of noise in different communities and settings (e.g., urban and rural), the difference between aircraft noise and ambient noise levels, and other human impacts; investigation of the effects of aircraft noise on children's ability to learn; and investigation of the trade-off between actions to reduce aircraft noise and the implications for pollutant emissions and particulate matter.

- Conduct further research on noise effects on animals. More work needs to be done in the area of hearing thresholds for various animal groups and the development of specific animal group weightings. Traditionally, researchers have used A-weightings, C-weightings, and flat sound pressure levels, which are not appropriate for use in describing noise stimuli for animals. In recent years, researchers have developed bird weightings (e.g., woodpecker weightings, owl weightings). Further work in this area is needed. Another area of research needed is in cumulative effects on animals to address not only aviation noise but also the combined impact of other sources (auto traffic, industrial, pollution, human interactions, etc.).

- Expand research on noise and vibration effects on people, structures, and land use compatibility. Additional research is needed in the effects of low-frequency noise and vibration, the evaluation of the effectiveness of sound insulation in residences and schools, examination of the occurrence and prevention of population encroachment into incompatible land use areas, identification of best practices and techniques for long-term compatible land use protection around airports, and identification of best practices for sound insulation techniques. Given industry's interest in a fielding a small supersonic business jet, research is also needed to establish sonic boom acceptability, including flight demonstration to validate theory.

- Continue to study effects of overflights on public lands. Research needs include refinement of existing noise models to consider adequately the unique technical issues posed by natural areas, definition of criteria for evaluating impacts on natural lands, and appropriate use of noise monitoring data in defining and assessing park soundscapes.

- Identify effective strategies to communicate information on noise. Additional research is needed to find the most effective ways to communicate to the public regarding airport 
noise. Good communication methods are needed to explain the basics of noise measurement, to make people aware of how to reduce impacts of the noise environment on their residences, and to alert prospective residents where noise-intrusive areas exist. Some airports have established better relationships with their neighbors through good noise communication, monitoring, and education programs. Further research is needed to help identify and disseminate these best practices.

\section{REFERENCES}

Center of Excellence for Aircraft Noise and Aviation Emissions Mitigation Partnership for Air Transportation Noise and Emissions Research (PARTNER): http://web.mit.edu/aeroastro/www/partner/.

Federal Aviation Administration Office of Aviation Policy, Planning, and Environment: http://www.faa.gov/about/office_org/headquarters_offices/aep/.

Federal Interagency Committee on Aviation Noise: http://www.fican.org.

Next Generation Air Transportation System Joint Planning and Development Office: http://www.jpdo.aero/site_content/index.html. 


\title{
Air Quality
}

\author{
JULIE ANN DRAPER \\ Federal Aviation Administration
}

KRISTI MCKENNEY

Port of Oakland

MARY LeE Vigilante

Synergy Consultants, Inc.

Chowen Chou Wey

National Aeronautics and Space Administration

\section{CRITICAL ISSUES}

During the 1990s, air pollution associated with aviation and airport-related sources became a prominent issue facing many of the large air carrier and general aviation airports in the United States. Today, criteria pollutants [carbon monoxide (CO), nitrogen dioxide, ozone and its precursors - oxides of nitrogen (NOx) and volatile organic compounds (VOCs) — sulfur oxides, and particulate matter $\left(\mathrm{PM}_{10}\right.$ and $\left.\mathrm{PM}_{2.5}\right)$ ] from airports account for less than $0.5 \%$ of total emissions in the United States (2003 GAO Report to Congress). Nevertheless, aviation sources, like those associated with other transport modes, can contribute to local air quality issues. For example, activity at a single large airport or at multiple airports in an area typically contributes up to five percentage points to an area's NOx inventory. Such effects may present especially difficult problems for future aviation capacity growth as 41 of the 50 busiest airports in the United States are located in ozone nonattainment and maintenance areas. Also, unlike other stationary or mobile sources, emissions from aviation-related sources are expected to increase in the future as air travel increases.

Recent litigation concerning airport development includes claims that airport operations are significant sources of air toxics, also known as hazardous air pollutants (HAPs), and cause adverse health effects in adjacent communities. With currently available tools, HAPs coming from aircraft are difficult to distinguish from those coming from other combustion sources, such as ground transportation. To understand better the role that aviation sources may play in this local air quality issue, the state of the science regarding the measurement and dispersion of HAPs, and their associated health effects requires continued advancement.

From a global perspective, the most prominent pollutants under investigation in the aviation community are those classified as greenhouse gas (GHG) emissions, such as carbon dioxide $\left(\mathrm{CO}_{2}\right)$. The International Civil Aviation Organization (ICAO) has been considering how international aviation might best pursue limits on or reduction of emissions of GHGs. Several means are continuing to be investigated at the international level, while individual countries (including the United States) consider their own domestic policies on these emissions from the aviation sector. 


\section{CURRENT STATE}

Aviation emissions research, in the United States is conducted in a number of different institutional settings, including federal and state governments (predominantly in California), universities, and private consulting firms. The principal federal programs include the following:

- The United States launched a 25-year plan for the NGATS, under the auspices of the multiagency Joint Planning and Development Office (JPDO), which includes the U.S. DOT, FAA, NASA, DoD, Department of Commerce, Department of Homeland Security, and the White House Office of Science and Technology Policy. NGATS involves an integrated effort to ensure that the future air transportation system meets air transportation security, mobility, and capacity needs while reducing environmental impacts. The JPDO structure includes an EIPT that is addressing a number of strategies to reduce aviation's air quality impact in absolute terms. The EIPT is also fostering science activities to reduce uncertainties in understanding aviation's atmospheric impacts to levels that enable appropriate action.

- TRB's Special Report 272: Airport Research Needs: Cooperative Solutions, which ultimately led to a congressionally authorized ACRP in 2003, identifies air quality as an area of potential research.

- NASA, the U.S. federal agency responsible for aeronautic and atmospheric research, conducts research on the atmospheric effects of aviation in collaboration between the Earth Science Enterprise and the Aeronautical Enterprise. Previously, the NASA Aeronautical Enterprise sponsored the Ultra-Efficient Engine Technology (UEET) Project, which primarily concentrated on the development of advance aircraft and engine technology in reducing emissions from the aircraft with gas turbine engines. However, NASA has canceled this effort and is in the process of reformulating its aeronautics program. It is unclear at this time what, if any, efforts on aviation emissions will continue.

- FAA has been working with other federal agencies, industry, academia, state organizations, and public interest groups to develop a National PM Roadmap. The genesis of this effort was an aviation particle emissions workshop held by the now defunct NASA UEET Project. Knowledge gaps and research needs were identified in the workshop, and a research roadmap was developed on the basis of the recommendation of U.S. experts from government agencies, academia, professional organizations, and aviation industries. In January 2004, FAA convened the first of a number of meetings to begin building on past work to develop the National PM Roadmap. At that meeting, representatives of FAA, NASA, DOD, EPA, states, manufacturers, airlines, airports, universities, and consultants were active participants, and five product groups were established: Policy Analysis, Measurement and Methodology, Impact Assessment, Technology Development, and Database Development. On the basis of subsequent meetings and interim work by the product groups, Roadmap participants reached agreement on the Roadmap content. In August 2005, the first version of the PM Roadmap was finalized. It presented an actionable plan for addressing PM emissions from aircraft engines. PM Roadmap implementation has begun, and will generate knowledge focused on near-term results to inform policy.

- FAA has developed a draft strategic framework to address aviation emissions in response to a GAO assessment of challenges posed by aircraft emissions. A status report was provided to the GAO in May 2005, and further work to incorporate the framework should take place under the EIPT discussed above. 
- FAA conducted a review of literature on particulate matter emissions from aircraft engines and based on the findings developed a First Order Approximation (FOA) to estimate the emission rate of $\mathrm{PM}_{2.5}$ by mode and jet or gas turbine engine model. FAA is currently working with the EPA, engine manufacturers, PM Roadmap participants, and ICAO working groups to revise and update the FOA continually on the basis of science advancements in PM measurement campaigns. The FOA is an interim methodology to demonstrate compliance with PM standards until a fully validated and representative PM emission factor database is developed. The FOA methodology was subsequently incorporated into the FAA's Emissions and Dispersion Modeling System, released in summer 2005.

- Two airport development program environmental impact statements (EISs) prepared subject to the NEPA were issued in 2005 that included a quantification of HAPs from airport sources. As a follow-up effort to its 2003 state of science report, FAA is currently assembling a HAPs Emissions Inventory Guidance document to establish a nationally consistent methodology for quantifying HAPs from aircraft engines and other airport sources. This guidance will be flexible to incorporate future data on HAPs emissions as it becomes available.

- The aviation community, including government agencies (FAA, EPA, and NASA), industry (manufacturers, airports, and airlines), academia, and professional organizations are planning to continue and possibly augment efforts to develop better ways of measuring PM and HAPs. For example, the aviation community is working with the SAE E31 subcommittee to develop methods for measuring PM for adoption by ICAO. In early 2004 the aviation community began the development of a national roadmap to address PM from aircraft sources, as noted above. This activity would be one of the components of the National PM Roadmap.

- The first Aircraft Particle Emissions Experiment (APEX) test was conducted in April 2004 and was the most extensive set of gaseous and particulate emissions data from an in-service commercial engine collected to date. APEX is a collaborative research effort of NASA, EPA, and DoD. Its main objective is to characterize gaseous and particulate emissions of NASA's DC-8 with CFM-56-2C1 engines to advance the understanding of particle emissions. Gaseous and particulate emissions were acquired by researchers and engine operating parameters were defined with assistance from manufacturers. The various participants in the APEX project have undertaken numerous activities related to the identifying emissions such as $(a)$ examining the effect of engine thrust on particulate emissions, $(b)$ simulating emissions at airports, and $(c)$ studying fuel effects on particulate emissions by varying fuel composition. APEX2 was conducted in August 2005, and APEX3 was conducted in October-November 2005. At APEX 2, the aircraft-engine combinations tested were a B737-700 with CFM56-6 engine and a 737-300 with CFM56-3 engine, and at APEX the aircraft and engines tested were a Learjet25 with CJ610 engine, an A300-600 with PW4158 engine, a B757 with RB211 Phase 2 engine, a B757 with RB211 Phase 5 engine, an ERJ with AE3007 engine, a B737-300 with CFM56-3 engine, and a B737-900 with CFM56-7 engine.

- FAA has sponsored the development of tools to evaluate aviation-related emissions (see "Tools" section). The System for Assessing Aviation's Global Emissions provides the capability to evaluate various options for reducing aircraft fuel burn and emissions over the whole flight regime. The Emissions and Dispersion Modeling System is FAA's required model for assessing emissions from aviation sources in the vicinity of airports for purposes of demonstrating compliance with the Clean Air Act and NEPA, which address a portion of concerns raised by the public and agencies. 
- FAA and NASA, in collaboration with Transport Canada, are sponsoring an Air Transportation Center of Excellence for Aircraft Noise and Aviation Emissions Mitigation, called the Partnership for AiR Transportation Noise and Emissions Reduction (PARTNER). The emissions element has grown to levels comparable to noise. The center completed three major research campaigns at active airports. Researchers conducted a PM measurement campaign at a North American airport. The data are already influencing models to assess aviation's PM emissions. Investigators also conducted a demonstration of the feasibility of using the continuous descent approach noise mitigation procedure, which also reduces emissions, for multiple aircraft at Louisville Airport. This research is transitioning into operation at Louisville International Standiford Field. The center also continues longer-term research projects on developing models to assess the socioeconomic effects of local and global emissions, determine the health impacts of HAPs, and reduce uncertainties in understanding aviation's impact on climate to levels that allow appropriate action.

- FAA has made substantive progress developing integrated noise and emissions analyses and economic assessment tools (see "Tools" section).

- FAA is implementing a grant-in-aid program to provide funding for alternative fuel vehicles at airports, including vehicle fleet conversions and infrastructure needed to support such equipment. The program does not have a research component.

- EPA has sponsored research to quantify or identify emissions from aircraft as they affect aircraft contrails, emissions from ground support equipment (GSE), and improved emissions rate data and modeling.

- The EPA-FAA Voluntary Emissions Reduction Stakeholder Process, convened in 1998, attempted to formulate a voluntary emission reduction program aimed at reducing the growth in NOx-related emissions from aircraft and GSE. Although the stakeholder process concluded in 2005 without reaching consensus on a national emission reduction program, the process generated joint EPA-FAA guidance on the Clean Air Act general conformity requirements as they apply to airport projects, and focused attention on the need for better data and tools to measure aviation emissions.

- In late 2003, EPA began a regulatory process for aircraft emissions to bring the U.S. aircraft engine emissions certification standards into alignment with those established by ICAO. The role of the ICAO Committee on Aviation Environmental Protection (CAEP) is to provide guidance and build consensus to set standards associated by individual member-states' efforts underway to understand and reduce aviation emissions, including more stringent gaseous emissions standards, development of methods to assess NOx emissions during climb and cruise, establishment of long-term technology goals, and assessment of operational procedures to reduce fuel burn and emissions.

\section{FUTURE VISION}

We need to develop the means to understand, quantify, and mitigate aviation emissions of traditional criteria pollutants, as well as pollutants of more recent concern such as PM and HAPs, diesel emissions, and GHGs. We also need to conduct the studies required to assess health risks scientifically, first to human beings and then to other sensitive organisms, from aviation emissions. Improved tools are needed to aid in communicating the conclusions of such studies to the general public. 


\section{RESEARCH NEEDS}

The research priorities involving aviation and air quality are summarized by affected types of pollutants below.

\section{Criteria Pollutants, HAPs, and GHGs}

- Improve the emissions quantification techniques and tools, including the ability to quantify volatile and nonvolatile PM emissions from aircraft, improve the modeling of pollutant concentrations around airports, and assess the need to evaluate health risks associated with exposure to these emissions.

- Research the emission reduction benefits of alternative fuels and additives for aircraft and alternative fuel use by ground support equipment and vehicles.

- Continue study of mitigation techniques to aid in development of emission reductions and evaluate such mitigation measures relative to operational, environmental, and economic consequences.

- Coordinate with international efforts to evaluate aviation's contribution to global GHG emissions to determine the best course of action for addressing appropriate limitations and reductions being asked of the industry. Assist in the furtherance of scientific understanding of these emission impacts in general, which remains a subject of much dispute.

- Develop methods of effectively communicating to the public the ranges of uncertainty in our analysis capabilities and risks to health associated with these pollutants.

\section{Criteria Pollutants, Noise, and Fuel Consumption}

- Conduct research on "clean" aircraft engines and available emissions reductions and understand the interplay of $\mathrm{NOx}, \mathrm{CO}, \mathrm{VOC}, \mathrm{PM}, \mathrm{CO}_{2}$, noise, and fuel consumption, as well as the interplay among the various emissions.

\section{PM and HAPs}

- Fill the key data gaps in the aircraft emissions estimation database for both PM and HAPs. Develop and maintain publicly available databases from peer-reviewed emissions data collected from exhaust plume of a small sample population of aircraft engines running at idle and increasing to maximum rated power. The aim for testing these various engine types and sizes within the sample population is to develop a data set that represents the national fleet.

- Collaborate with SAE E-31 and other stakeholders including ICAO CAEP to develop a detailed aircraft engine emissions measurement protocol for PM that will provide consistent and validated methodologies to acquire accurate aircraft engine emissions data.

- Continue working with stakeholders such as NASA, FAA, EPA, academia, and industry to collect and analyze PM and HAP data. To date, FAA has worked with the aviation community to collect emissions data from a growing sample of specific aircraft and engines at several airports in the United States. Currently, FAA and others have accumulated enough data and information to begin a review of critical needs, such as information gaps, and how these needs can be addressed from the available information. 
- Collaborate with FAA, EPA, and other stakeholders to create and implement a standardized guideline for assessing HAPs from aircraft engines and other airport emission sources. Move from strictly looking at what is currently known about aviation-related HAPs to developing a standardized guideline that takes into account $(a)$ various HAPs assessment methodologies used by airports to assess environmental impacts of planned construction; $(b)$ new data collected from aircraft parked off-runway with engines running at predetermined thrust settings; (c) data collected at locations where aircraft begin take-off operations on the runway; (d) ambient airport monitoring data; $(e)$ research work produced by the FAA-NASA-Transport Canada Center of Excellence; and $(f)$ a review of the latest published information on aircraft HAPs to produce a comprehensive, fleet-representative dataset.

- Work with other stakeholders to determine the need for characterization of health risks potentially associated with aviation-related HAP emissions. FAA will consider the development of guidance to conduct a health risk assessment upon completion and implementation of the guidelines for conducting HAPs emissions inventories. Current PARTNER research is underway to identify uncertainties and scientific priorities associated with risk assessments of HAP emissions related to aviation sources, particularly aircraft engines. If research outcomes are deemed to support the necessity for further effort, a risk assessment-risk management framework may be developed for use by airports to provide a public health perspective for HAPs from aviation sources and provide meaningful risk information to surrounding communities.

\section{REFERENCES}

APEX website: http://www.nasa.gov/centers/glenn/projects/APEX.html.

EPA website: http://www.epa.gov/oar/oaqps/greenbk/o8index.html.

Federal Aviation Administration. Select Resource Materials and Annotated Bibliography on the topic of Hazardous Air Pollutants (HAPs) Associated with Aircraft, Airports, and Aviation. 2003, http://www.faa.gov/regulations_policies/policy_guidance/envir_policy/media/HAPs_rpt.pdf.

Glenn Measurement website: https://particles.grc.nasa.gov/measurement.html.

General Accounting Office. Report to Congress, 2003.

PARTNER website: http://web.mit.edu/aeroastro/www/partner/.

TRB Special Report 272: Airport Research Needs: Cooperative Solutions. Transportation Research Board of the National Academies, Washington, D.C., 2003, http://trb.org/news/blurb_detail.asp?id=1266. 


\title{
Water Quality
}

\author{
RICHARD S. DAVIS \\ Beveridge \& Diamond, PC \\ Claudio H. Ternieden \\ Water Environment Research Foundation \\ (formerly with American Association of Airport Executives)
}

\section{CRITICAL ISSUES}

The effect of airport operations on water quality has been garnering attention as regulators look beyond the more obvious sources of water pollution (i.e., end-of-pipe industrial waste discharged into large water bodies) and attempt to address issues such as storm water runoff and other nonpoint sources. Airports, which typically include large expanses of impervious surfaces and host activities that can generate discharges of potential contaminants (e.g., vehicle and aircraft fueling, maintenance, and deicing), have been subject to the requirements of the Clean Water Act's regulations for more than a decade, but the application of these rules to the unique operating environment of airports still is being refined. More recently, other water quality initiatives, such as the identification of impaired water bodies and the efforts to set total maximum daily loads (TMDLs) for specific pollutants for those water bodies, have added complexity to what initially seemed a straightforward permitting regime.

The relationship - and occasional tension-between protecting the environment and protecting the safety of the traveling public has arisen in the water quality context in two distinct areas:

- Deicing and anti-icing agents, used to ensure safe operations in freezing temperatures or other conditions in which frost may form on aircraft surfaces, may have environmental impacts. Although some questions have been raised about potential releases of air emissions from deicing agents, most attention has been focused on the potential for deicing agents to become entrained in storm water and carried through the storm sewer system into nearby bodies of water. Recent improvements in deicing technology have allowed airlines to minimize the use of deicing agents, but the desire to reduce potential pollutants from entering these waters must be balanced by the need to prevent aviation accidents. In addition, recent studies have looked at the potential toxicity of certain additives to deicing fluids. Management of these constituents by airports may be more difficult, because the precise composition of the additive packages is typically considered proprietary information by the manufacturers.

- For historical reasons, many airports are located on or adjacent to large bodies of water (e.g., Los Angeles International Airport; San Francisco International Airport; Logan International Airport, Boston, Massachusetts; Ronald Reagan National Airport, Washington, D.C.,; and John F. Kennedy International Airport, New York). These water bodies, along with associated marshes and other wetlands, often provide habitat for a large number of birds and waterfowl known to cause severe aircraft damage or aircraft crashes. Some of these avian species are protected federally. Enhancing and preserving the water quality of these habitats is an 
important goal of the Clean Water Act. At the same time, birds inhabiting these areas present a hazard to aircraft, especially during approach or departures at altitudes of 2,000 ft or less, within which more than $90 \%$ of aircraft-wildlife strikes occur. The incidence of bird strikes is rising, attributable in part to significant improvements in the quality of these habitats and increasing air traffic.

\section{CURRENT STATE}

Research is conducted by airports, government agencies, and industry organizations:

- Airports are conducting airport-specific research. Some airports have committed substantial resources to studying the quality of their discharges, either for purposes of developing site-specific data in the course of permitting proceedings or for the purpose of making decisions on the deployment of technologies to minimize overall impacts. As more of these data become available, we will be better able to generalize about discharges from airports.

- EPA is continuing to study whether it would be appropriate to develop technologybased Effluent Limitations Guideline (ELG) addressing discharges from airport deicing operations. Data collection for this effort, including questionnaires directed to key industry sectors and site visits to airports, began in 2005 and is expected to continue in 2006. This evaluation is required by law to be completed no later than September 2007 and may result in the issuance of an ELG regulation containing numeric limitations, best management practices, or no limitations for some or all industry subcategories. In the meantime, some states have set a variety of numerical limits for individual permits.

- The SAE's Aerospace Division has developed and adopted standards limiting the aquatic toxicity of new formulations of Type I aircraft deicing fluids. The society remains open to the possibility that those standards may need to be made more stringent and also may be open to the imposition of similar environmental performance standards for other types of aircraft deicers and for pavement deicing products.

- Research conducted to date on the biological effects of deicing agents has been conducted at room temperatures, not representing real-world temperatures present when most airports apply the agents. Since most aquatic communities are cold blooded, temperature affects their respective physiologies and oxygen demands. As a result, room temperature bioassays may not be providing a true picture of how these agents are truly affecting the dissolved oxygen needs of aquatic resources. Bioassays performed at cold water temperatures would provide data for water temperature conditions existing in most cases when the agents are applied and discharged.

- Research on constructed wetlands is being conducted as an alternative means of treating storm water runoff and industrial waste using holding areas stocked with plant communities designed to mimic the functions of wetlands. As adapted to airport environs, these artificial wetlands also must be designed to minimize wildlife hazards. Several prototypes have been constructed or are in the planning stage at airports.

- FAA, EPA, U.S. Fish and Wildlife Service, Department of Agriculture, and DoD have been coordinating to address aircraft-wildlife strikes more effectively under a 2003 interagency Memorandum of Agreement. FAA also is working with the U.S. Fish and Wildlife Service on a separate agreement to address migratory bird issues and aviation in response to Executive Order 13186. 
- Airports are improving monitoring techniques. Advances have been made in technology that allow for continuous and real-time monitoring of airport storm water. A number of airports recently have installed systems that will provide useful data, as well as valuable experience with such technology.

- The American Association of Airport Executives is in the process of gathering information about existing and proposed plans so that trends and best practices for controlling storm water can be more easily identified. Currently, there is no comprehensive source of information about airport storm water plans other than the dated material offered by the EPA in 1990 and what is available from individual state environmental agencies.

\section{FUTURE VISION}

We need to encourage the development of programs to address a number of specific aviation needs relating to water quality:

- A database or other system of collecting and analyzing information about airport storm water plans;

- A means of sharing information on pavement deicing studies between the aviation and the highway sectors, specifically to compile lessons learned about water quality impacts and potential corrosive effects of particular deicing agents or practices;

- Education of regulatory agencies and environmental groups about the interrelationship between wildlife management at airports and the hydrological function of wetlands and dissemination of research that seeks to reconcile the two; and

- A forum for the discussion and dissemination of research on alternatives to chemical deicing, storm water and waste water management practices at airports, and new technology that could assist in compliance with water quality requirements.

\section{RESEARCH NEEDS}

Specific research needs involving aviation and water quality are the needs to

- Assess biological impacts of deicing agents in real-world conditions. Bioassays should be conducted at colder water temperatures replicating conditions existing in most cases when the agents are applied and discharged. In addition, more research needs to be conducted to determine whether additives contribute to water quality problems at airports.

- Develop new deicing agents. The advertised environmental benefits of new deicing agents need to be matched by study of potential adverse effects of new agents on operations and equipment (e.g., corrosivity of potassium formate, corrosion protection offered by triazole-free aircraft deicing agents).

- Find alternatives to chemical deicing agents. Reducing reliance on chemical deicing agents can have significant benefit in terms of water quality. Additional research is needed to develop additional nonchemical deicing methods and to reduce the costs and improve the functionality of those already shown to be feasible technologically.

- Refine storm water management techniques. Continued research into the control and 
treatment of storm water in an airport environment is needed to improve water quality and reduce compliance costs.

- Develop appropriate discharge obligations for airports. Airports may be subject to regulatory requirements under several different water programs, including the National Pollutant Discharge Elimination System, TMDLs, and water quality certification for infrastructure construction. The aviation sector needs to identify and to participate in the development of these programs at the state and national level, and discharge obligations of airports need to be assessed accurately in order to provide a sound baseline for project designs.

- Further research and develop best practices for reducing the role of wetlands and water bodies in attracting wildlife hazards to airport environs without compromising their hydrological function or reducing habitat for threatened and endangered species. This may include identification of plant species or plant communities that do not attract the kind of wildlife that poses a hazard to aircraft operations, more sophisticated methods of assessing habitat quality, and better mapping of wetlands and other aquatic habitats.

\section{REFERENCES}

EPA website: http://www.epa.gov/ost/guide/airport/index.html.

FAA website: http://www.faa.gov/arp/environmental/5054a/wildhazmou.pdf.

U.S. Government Printing Office, 2001. Executive Order 13186, 66 Federal Register 3853, January 17, 2001. 


\title{
Environmental Process
}

\author{
John E. PuTnaM \\ Kaplan Kirsch \& Rockwell, LLP
}

\section{CRITICAL ISSUES}

Consideration of environmental issues at airports is often a complex and inefficient process, both in terms of environmental documentation for proposed development and in terms of ensuring that airport operations meet applicable regulatory and other requirements. Protracted environmental documentation may impede development and increase costs on the one hand and fail to realize important objectives in terms of resource protection and preservation of quality of life on the other. Agency enforcement of regulatory standards in a command-and-control mode may fail to provide environmental benefits in proportion to financial costs.

The form and implementation of environmental review and compliance processes are important for determining whether critical stakeholder needs are met. A complex set of laws and policies guides airport development, airspace changes, compliance with environmental requirements, and development of aviation technology and products. Environmental review, rule making, and enforcement roles are shared among a number of entities at the federal, state, and local levels (e.g., airport owners, FAA, EPA, Army Corps of Engineers, Fish and Wildlife Service, state environmental agencies, and municipalities). These activities often are undertaken in an uncoordinated way that can increase the time, cost, and difficulty of project approval and compliance with environmental requirements but that may or may not advance the goals established for the process. Public opposition and litigation on environmental grounds also add time and increase the uncertainty of the environmental review processes.

Environmental issues associated with aviation are critically important to the future development of aviation infrastructure. Environmental concerns are primary factors constraining the development of additional airport capacity in many areas. Both the perception and the reality of noise, air pollution, traffic congestion, and other environmental effects - as well as the level of trust or confidence in analyses of these effects and the ability to mitigate them-drive political, legal, and other decisions that affect the ability to expand the aviation system. Similarly, decisions regarding aviation have real effects on the environment that may or may not be fully consistent with federal, state, and local environmental assessments preceding the decisions. Accordingly, an improved understanding of the strengths and weaknesses of the environmental review and compliance processes associated with aviation is critical.

\section{CURRENT STATE}

In the fall of 2000, the aviation industry and Congress gave increased attention to additional capacity at congested airports. Many stakeholders identified environmental processes as among the causes for delays in implementing capacity initiatives. Government and industry entities increased efforts to evaluate how well current environmental processes work within the aviation context and to identify means of better meeting the goals of environmental requirements. These efforts included the DOT's Report to Congress in 2001, Environmental Review of Airport 
Projects, and the GAO's Aviation and the Environment Airport Operations and Future Growth Present Environmental Challenges (August 2000). Industry organizations such as Airports Council International and the American Association of Airport Executives identified proposals to address perceived shortcomings of current processes. Environmental organizations and local governments also have expressed concerns with the manner in which aviation environmental issues are addressed.

FAA has implemented recently streamlining initiatives identified in the DOT's Report to Congress. In 2002, the president issued Executive Order 12374 to promote environmental stewardship and expedited environmental reviews of high-priority transportation infrastructure projects, including airport infrastructure. Congress included provisions intended to streamline environmental review for aviation projects in Vision 100, the FAA reauthorization bill for 20042007. In 2003, a task force appointed by the Council on Environmental Quality (CEQ) issued a report identifying ideas for possible reform of federal environmental reviews; CEQ is implementing some of these ideas and considering others. In June 2004, FAA issued an updated version of its agencywide guidance on environmental policies and procedures (Order 1050.1E). In December 2004, FAA issued a draft update to the Airport Environmental Handbook (FAA Order 5050.4B). Because of extensive comments, FAA does not expect to issue the final order until spring 2006. Despite these initiatives, there is still a considerable gap in knowledge regarding aviation-related environmental review and compliance processes. There has been relatively little study conducted by neutral parties to determine objectively and empirically the effectiveness of these processes and the causes of the sometimes lengthy time periods to review and approve airport projects.

\section{FUTURE VISION}

We need to improve the process of conducting environmental reviews and ensuring environmental compliance at airports. This effort will require improved analytic tools, incentives for and new methods to ensure timely interagency cooperation, elimination of procedural requirements that slow and complicate processing without producing clear benefits in terms of decision making, consideration of alternatives to traditional forms of regulation, and use of communications technologies to enhance the intelligibility and transparency of environmental processes to which the public has access.

\section{RESEARCH NEEDS}

Research is needed to support improvements in environmental review and compliance processes to achieve timely development of aviation services and the protection of the environment. Environmental review and compliance processes should inform decision makers and the public of the environmental impacts of projects, support selection and implementation of projects that promote transportation and environmental goals, ensure compliance with environmental requirements, work within reasonable and predictable timeframes, and minimize cost. Objective and empirical research regarding the effectiveness, efficiency, accuracy, and shortcomings of environmental processes applicable to aviation, as well as potential means to improve these processes, would be useful to policy makers in evaluating whether existing processes should be 
changed and in what manner. Many of the research needs arise primarily in the context of the environmental review of new aviation projects, although others relate primarily to ongoing compliance with environmental requirements. Both the environmental review and compliance contexts are important to the protection of the environment and the health of the aviation industry.

Specific research needs involving the aviation environmental process are the needs to

- Determine the amounts of time that environmental review and compliance processes currently require for various airport projects and determine how such timelines vary by project type, regional location, and impacts;

- Identify the probable causes of any added approval time, including multiagency coordination issues, genuine environmental problems, inability to mitigate, disputes over purpose and need, community opposition, project revision, and lack of resources;

- Locate critical bottlenecks in the environmental process and develop possible solutions that would still meet process goals;

- Assess the effects of current and forthcoming streamlining and other measures, as well as the effects of implementation of new regulations or guidance (e.g., the new FAA Order 5050.4B);

- Assess the effectiveness of environmental documents' communication of impacts, risk, and complex topics (e.g., noise, air pollution, air toxics, capacity, and forecasts) to the public;

- Develop approaches for conveying environmental information in the aviation context in a brief, accessible, and meaningful way;

- Evaluate the forecasts, assumptions, and predictions made in previous environmental reviews in light of actual experience;

- Consider the effectiveness of sustainable practices and programs (including environmental effects, costs and benefits, and relationships with affected communities);

- Review the adequacy of mitigation tools available to address community concerns and opposition, as well as the effects of mitigation on the process (this effort links with research needs listed in the noise, air quality, water quality, and tools sections);

- List the factors critical to addressing community opposition and concerns;

- Asses the effectiveness of environmental management tools, as well as alternatives to the command and control compliance model in the aviation context;

- Study the effects and adequacy of legal processes affecting aviation environmental planning, such as land use and metropolitan transportation planning processes, occupational safety litigation, and takings and nuisance litigation; and

- Evaluate the effectiveness of components of the environmental review process and develop measures to benchmark best practices.

\section{REFERENCES}

Council on Environmental Quality. Compendium of Best Practices. http://ceq.eh.doe.gov/ntf/compendium.

Council on Environmental Quality NEPA Task Force, Modernizing NEPA Implementation, September 2003. http:/ceq.eh.doe.gov/ntf/report/finalreport.pdf. 
Department of Transportation, Report to Congress, Environmental Review of Airport Projects, 2001.

Posted at http://www.faa.gov/ARP/environmental/5054a/RTCenv.pdf.

Executive Order 13274, Environmental Stewardship and Transportation Infrastructure Project Reviews, September 18, 2002. Posted at http://ceq.eh.doe.gov/nepa/regs/eos/eo13274.html.

Federal Aviation Administration, FAA Guide to the Best Practices for Environmental Impact Statement Management, 2002. Posted at http://www.faa.gov/arp/environmental/5054a/bestprac.cfm.

Federal Aviation Administration and National Organization of State Aviation Officials, Federal and State Coordination of Environmental Reviews of Airport Improvement Programs, March 2002. Posted at http://www.faa.gov/ARP/environmental/5054a/EIS_FAA_NASAOreport.rtf.

Federal Aviation Administration, Environmental Management Systems and NEPA Adaptive Management, May 2004. Posted at

http://www.faa.gov/regulations_policies/policy_guidance/envir_policy/media/WebEMSAdaptive.pdf.

Federal Aviation Administration, Draft Order 5050.4B, December 2004. Posted at http://www.faa.gov/arp/environmental/5050_4B/Index.cfm

General Accounting Office, Aviation and the Environment Airport Operations and Future Growth Present Environmental Challenges, August 2000. Posted at http://www.gao.gov/archive/2000/rc00153.pdf. 


\title{
Tools
}

\author{
JULIE ANN DRAPER \\ Federal Aviation Administration
}

\section{CRITICAL ISSUES}

The adverse environmental by-products of aviation increasingly affect civil aviation's capacity to grow and to operate unrestrained nationally and internationally. Although there are multiple byproducts and interdependences that are important to understand, noise and air pollutant emissions are particularly critical and more directly dependent on aircraft and engine design. Delivering technologically and economically feasible decreases in noise and emissions is a growing challenge. Substantial progress already has been made, particularly in reducing jet engine noise. However, passenger and cargo aircraft and gas turbine engines are maturing technologies, and the growing complexity of aircraft systems compels an interdisciplinary approach to aircraft design to achieve future advances. Moreover, progress in noise and emissions mitigation must employ a mix of source reduction technologies with operational procedures, controls, and land use management to reduce exposure to the sources. The challenge is to understand the interdependencies between aircraft noise and aviation emissions and among various emissions to optimize mitigation strategies and to minimize environmental impacts as a whole. Exploiting continuously increasing computing power will play an important role in achieving that understanding.

We must develop superior decision support tools that enable an interdisciplinary approach to assessing aviation environmental impacts and interrelationships. These tools must give decision makers - including the aviation industry, government, and the public - the information needed to develop responsive strategies that allow aviation to grow in an environmentally responsible manner. The aviation industry needs to analyze the noise and emissions interdependencies in both the design and operating contexts. Government agencies need to assess the consequences of proposed environmental actions and policy decisions in terms of the effects on noise and air pollutant exposure. The public needs reliable and clear information on noise and emissions impacts to participate effectively in decision making that could affect health and welfare. Assessing impacts and interrelationships is a complex issue, and it will take time to develop interdisciplinary decision support tools. Meanwhile, it is important to maintain a state-of-the-art analytical capability to support ongoing needs for aviation noise and emissions analyses.

\section{CURRENT STATE}

FAA has been at the forefront of developing and deploying models to evaluate aircraft noise and aviation air pollutant emissions around airports, notably the Integrated Noise Model and the Emissions and Dispersion Modeling System. FAA also has developed a Model for Assessing Global Exposure to Noise from Transport Aircraft and more recently developed the System for Assessing Aviation's Global Emissions, which estimates aircraft fuel burn and emissions over the entire international and domestic flight regime. NASA is at the forefront of developing 
aircraft and engine design and analyses models that also encompass noise and emissions predictive capabilities. These models include Aircraft Noise Prediction Program, Advanced Vehicle Analysis Tool for Acoustics Research, and NASA Engine Performance Program.

Efforts to address aircraft noise and aviation air pollutant emissions issues have advanced largely along independent paths. There are separate modeling tools, research projects, analyses, metrics, and decisions. This reflects the complexities of each issue as well as the makeup of the broader aerospace community (including manufacturers, academia, and government entities), which historically has treated noise and air pollutant emissions as separate disciplines. Although there has been some crossover in recent years, such as incorporating aircraft performance data from noise models into emission models, the current level of integration is not sufficient to meet today's and the future's needs.

\section{FUTURE VISION}

We need to base future environmentally responsible aviation policy and rule making on a new, interdisciplinary approach. This approach must be made as affordable as it is effective. Tools are needed to assess and communicate more effectively environmental effects, interrelationships, and economic consequences based on integrated analyses. These tools will enable more informed federal policy and budgetary decision making, and facilitate international agreements on standards, recommendation practices, and mitigation option. Existing analytical tools are inadequate to assess interdependencies between noise and emissions or analyze the cost-benefit of proposed actions. Accordingly, FAA is developing a robust new comprehensive framework of aviation environmental analytical tools and methodologies to perform these functions. The longterm aim is to provide a seamless, comprehensive set of tools to address all aspects of noise and emissions. The elements of this framework will include the following:

- Environmental Design Space (EDS) to provide integrated analysis of noise and emissions at the aircraft level;

- Aviation Environmental Design Tool (AEDT), comprising EDS and other integrated aviation noise and emissions modules, to provide integrated capability of generating interrelationships between noise and emissions and among emissions at the local and global levels; and

- Aviation Environmental Portfolio Management Tool (APMT), comprising AEDT and other modules, to provide the common, transparent cost-benefit methodology needed to optimize national aviation policy in harmony with environmental policy.

This framework of tools will allow

- Government agencies to understand how proposed actions and policy decisions impact and are impacted by aviation noise and emissions;

- Industry to understand how operational decisions impact and are impacted by proposed projects affecting aviation noise and emissions; and

- The public to understand how actions by government and industry impact and are impacted by aviation noise and emissions. 
FAA has asked TRB to assist it in defining the attributes and requirements of the new tool set. A series of workshops were held in 2004 and 2005 to gather input from experts to aid in developing the tool set. Almost 70 specialists from academia, industry, government, and environmental groups attended the workshops. The TRB Developing Aviation Environmental Design and Aviation Environmental Portfolio Management Tools Committee reviewed and evaluated the initial development effort. The committee's findings and recommendations are documented in letter reports and, in particular, recommended that the FAA continue to develop the AEDT and APMT. The FAA is continuing to develop the AEDT and APMT, incorporating the TRB workshop findings on requirements and process as appropriate.

\section{RESEARCH NEEDS}

An interdisciplinary approach to noise and emissions modeling builds on continued improvement of individual noise and emissions modules. Related tasks include developing and validating databases and methods used to assess aircraft noise exposure and impacts, aviation pollutant emissions and impacts on air quality, and global aviation emissions and impacts on climate. Specific research needs involving aviation environmental tools follow:

- For EDS and AEDT, combine existing NASA acoustics and engine emissions modules into an integrated package for evaluating interrelationships between noise and air pollutant emissions, taking into account aircraft cost considerations, design, and operational factors (e.g., time in mode). We must create the software architecture, design module links, and harmonize database architecture. We must create user interface and output protocols. This effort also includes troubleshooting and optimizing the software design.

- For APMT, integrate the AEDT with suitable traffic and econometrics modules and socioeconomic data. This effort also includes creating a user interface and output protocol, troubleshooting, and optimizing the software design.

- For both the AEDT and the APMT, conduct a quantitative assessment of uncertainty. This assessment will provide guidance on the level of confidence that we can place on tool outputs and encourage international acceptance. The assessment also will provide a research road map for improving the tools with specific, quantitative metrics for measuring this improvement.

FAA is pursuing development of both the AEDT and APMT, and imagines uses ranging from design and technology impact studies to airport improvement projects to noise and emissions certification standards rule making. FAA is seeking participation from academia, industry, government, and environmental groups on this initiative.

\section{REFERENCES}

Connor, T., and L. Q. Maurice. Aviation's Impact on the Environment: Addressing Interrelationships. Journal of Aviation Management, 2005, pp. 67-77.

Transportation Research Board. Letter Report: Workshop \#1: FAA Aviation Environmental Design Tool, 2004. Posted at http://trb.org/publications/reports/aedt.pdf.

Transportation Research Board. Letter Report: Workshop \#2: FAA Aviation Environmental Design Tool and Aviation Portfolio Management Tool, 2005. Posted at http://trb.org/publications/reports/ 
aedt_april_2005.pdf.

Transportation Research Board. Letter Report: Workshop \#3: FAA Aviation Environmental Design Tool and Aviation Portfolio Management Tool, 2005. Posted at http://trb.org/publications/reports/ aedt_may_2005.pdf. 


\title{
Technology Deployment
}

\author{
Richard L. Altman \\ United Technologies Corporation
}

\section{CRITICAL ISSUES}

Research into the fundamental effects of aviation on the environment of the type described in the previous sections of this paper cannot be converted into improvements that would reduce those effects unless the recommended technologies are actually developed and deployed in the field. The pace and scope of deploying new technologies within the aviation enterprise in an increasingly complex future depends on numerous factors, many of which are not well understood. These factors include

- How to introduce new technologies within the existing aviation system interface constraints. Demonstrating the efficacy of new technology to meet its intended environmental goal is necessary but not sufficient to ensure its deployment in aviation. New technology intended to address environmental performance must meet the same high reliability, durability, maintainability, and increasingly significant security standards applied to other components of the aircraft. These requirements can be a barrier to deployment by disqualifying some technologies entirely, mitigating the net environmental gain, or producing high economic penalties.

- How to make new technologies marketable. Manufacturers outside aviation or conglomerates may not perceive aviation to be a sufficiently large market or have a viable business model to support development of products tailored to this sector. For example, there is minimal fuel cell or microturbine research concentrating on potential airport applications although it could be used in many pieces of airport equipment.

- How to determine costs and benefits of new technologies. The economic costs and benefits to end users of technology that has an environmental benefit to communities are not well understood, and there is no widely accepted metric by which to measure them.

- How to develop optimal trade-offs. The interrelationship of aircraft components may force suboptimization of one technical characteristic to avoid sacrificing others. For example, innovations in engine technology resulted in quieter, more fuel-efficient aircraft but increased emissions of NOx.

- How to stimulate commercial risk-taking. Government research programs in the United States are not developing new technology to a level that would allow private enterprise to adopt it at reasonable risk. In the past, NASA sponsored technology to the system demonstration level [referred to as Technology Readiness Level 6 (TRL6) in NASA nomenclature]. For example, during the 1980s, NASA, under its aircraft energy efficiency program, sponsored both engine and aircraft full-scale demonstrations that were taken to TRL6, which produced significant innovation in commercial products in the ensuing years. No such programs exist today.

- How to meet future demands. At the same time that technology innovation has flagged, the national needs for dramatic improvements in reducing aviation's impact on the environment have become more obvious. The NGATS is currently being defined by the JPDO to 
enable up to a threefold capacity increase in air traffic. The JPDO incorporates an environmental plan to ensure that there is no growth in environmental exposure in the United States as this growth occurs, but such a plan depends on deployment of advanced technology.

- How to address future issues. Emerging issues, particularly those that are not governed by aviation specific regulatory bodies at the time of their emergence (e.g. particulates, HAPs, deicing) require thorough aviation specific research before optimum solutions can be identified and often even longer time periods before appropriate technologies can be designed, produced, and introduced into the market. Without such definition well in advance of control requirements being defined, timely development and deployment of solutions are not possible.

\section{CURRENT STATE}

Aviation faces the challenges of a maturing industry. The pace of innovation has decreased as the aviation industry has matured. Technological advances over the past 50 years have resulted in aircraft and engines that are increasingly quieter, more fuel efficient, and produce fewer pollutants. During the last decades of the 20th century, new commercial aviation systems were deployed at a rapid pace, filling voids in aircraft size and range and frequently following on the heels of military aircraft developments in similar size and speed classes. At this time, the feasible range of speed and size for commercial aircraft has been explored and few voids exist. Most of the current technological innovation takes the form of improvements to existing aircraft types, and the economic barrier to replacing an existing product in the same size and speed class is high.

Some research is beginning to be conducted that address critical deployment issues. For example, the issue of optimal technology trade-offs in aircraft design was first evaluated by a consortium of airline operators and manufacturers in support of international regulatory investigations earlier this decade. It is being addressed further under FAA's Environmental Design Space initiative. It is anticipated that the shortfall in environmental capacity resulting from the planned threefold increase in aviation activity will be identified by the JPDO Evaluation and Analysis Division.

\section{FUTURE VISION}

We need additional data, analysis, and tools to improve deployment of environmental technologies to address the collective goals of all its participants. The data and analysis should cover the full spectrum of issues effecting deployment, be usable by all interests, and enable informed decision making by creating the best possible understanding among and between the engaged enterprise components. We also need means of communicating this information as effectively as possible across the aviation enterprise and to those who interface with it. We envision that the generation of this information will in turn lead to a reduction in the barriers to technology deployment and thus allow reductions in the impact of aviation on the environment. 


\section{RESEARCH NEEDS}

The specific research needs identified to address the critical issues in technology deployment best are

- Conduct research on business processes to include identification and investigation of case studies from other transportation modes and similar technology intensive industries. Determine how technology innovation has best occurred in other industries that depend on environmental performance and which are in similar mature positions on the S curve of industry life cycle. Such management science studies can produce lessons learned applicable to aviation as it migrates through its maturity phase.

- Develop an adequate benchmark of case studies of specific technologies that had to meet equally high standards as they have progressed from the demonstration to implementation or insertion at a systems level. Such a set of studies can alert evaluators to the scope and magnitude of penalties that may be anticipated in deployment of new aviation environmental technologies.

- Target research and review case studies to identify the transferability of environmental technologies first deployed in other industries to aviation. This in turn would establish aviation feasibility for systems shown to be reliable and safe and could enable users to create strategies that cross multiple markets. Conversely, while aviation may not be the largest market for some technologies, it may have characteristics (contained or controlled test space) that make it desirable for beta (user insertion) testing of new products targeted for multiple markets. Offers by the aviation industry to house such tests could speed insertion into the general market. Research should be targeted to identify opportunities where this approach may be attractive.

- Research is needed to determine the costs and benefits of environmental improvements. While the acquisition and recurring cost consequences of new technologies are available to operators from manufacturers, the research need is for third-party (neither seller nor buyer) monetization of benefits to operators if existing economic penalties are ameliorated through improved product performance. Amelioration here can take the form of reduced fees, capacity constraints, purchasing of environmental credits, and operational changes such as noise abatement flight tracks. For DoD operations, amelioration may take the form of reducing tanker requirements, training costs, or maintenance costs if the most effective basing cites are unavailable. This research recommendation follows the initiative to develop a balance sheet of costs and benefits, which was an outcome of the Aviation Portfolio Management Tool workshop conducted by TRB at the request of FAA during the first quarter of 2005.

- Continue research to determine optimal trades among environmental factors in aircraft design at least into the production flight test phase where product form, fit, and function are established.

- Research ways to reduce the risk of introducing new technology and stimulating commercial investment. For example, quantify, in an objective manner, the percent chance of success and payoffs for key technologies and systems of multiple technologies. The DoD-NASA technology readiness process, which has existed since the 1990s, can be used as a model to collect data on projects at all risk levels.

- Research that quantifies the benefits-costs of developing or deploying advanced technology to meet NGATS capacity requirements to the satisfaction of all enterprise 
components needs to be executed in a timely manner. By identifying enterprise pull (motivated by potential growth) this research could define a basis for market-based deployment based on national objectives.

- Research means of establishing mechanisms to detect at the earliest possible occasion new environmental requirements that could impact aviation.

- Identify and evaluate where government action (other than research) has accelerated identification and deployment of technology in aviation and in other industries both inside and outside the United States. Careful selection of these examples to ensure that they have similar key characteristics as aviation will be critical to this initiative's success. Better understanding of how such tools can be used most effectively would enable the U.S. government to speed deployment of aviation technologies that would benefit the environment.

\section{REFERENCES}

Environmental Integrated Product Team. Technology Pathways - Assessing the Integrated Plan for Next Generation Air Transportation System. (ISBN 0-309-65283-PDF) Appendix G, Draft Plan, 2005. 


\section{THE NATIONAL ACADEMIES Advisers to the Nation on Science, Engineering, and Medicine}

The National Academy of Sciences is a private, nonprofit, self-perpetuating society of distinguished scholars engaged in scientific and engineering research, dedicated to the furtherance of science and technology and to their use for the general welfare. On the authority of the charter granted to it by the Congress in 1863 , the Academy has a mandate that requires it to advise the federal government on scientific and technical matters. Dr. Ralph J. Cicerone is president of the National Academy of Sciences.

The National Academy of Engineering was established in 1964, under the charter of the National Academy of Sciences, as a parallel organization of outstanding engineers. It is autonomous in its administration and in the selection of its members, sharing with the National Academy of Sciences the responsibility for advising the federal government. The National Academy of Engineering also sponsors engineering programs aimed at meeting national needs, encourages education and research, and recognizes the superior achievements of engineers. Dr. William A. Wulf is president of the National Academy of Engineering.

The Institute of Medicine was established in 1970 by the National Academy of Sciences to secure the services of eminent members of appropriate professions in the examination of policy matters pertaining to the health of the public. The Institute acts under the responsibility given to the National Academy of Sciences by its congressional charter to be an adviser to the federal government and, on its own initiative, to identify issues of medical care, research, and education. Dr. Harvey V. Fineberg is president of the Institute of Medicine.

The National Research Council was organized by the National Academy of Sciences in 1916 to associate the broad community of science and technology with the Academy's purposes of furthering knowledge and advising the federal government. Functioning in accordance with general policies determined by the Academy, the Council has become the principal operating agency of both the National Academy of Sciences and the National Academy of Engineering in providing services to the government, the public, and the scientific and engineering communities. The Council is administered jointly by both the Academies and the Institute of Medicine. Dr. Ralph J. Cicerone and Dr. William A. Wulf are chair and vice chair, respectively, of the National Research Council.

The Transportation Research Board is a division of the National Research Council, which serves the National Academy of Sciences and the National Academy of Engineering. The Board's mission is to promote innovation and progress in transportation through research. In an objective and interdisciplinary setting, the Board facilitates the sharing of information on transportation practice and policy by researchers and practitioners; stimulates research and offers research management services that promote technical excellence; provides expert advice on transportation policy and programs; and disseminates research results broadly and encourages their implementation. The Board's varied activities annually engage more than 5,000 engineers, scientists, and other transportation researchers and practitioners from the public and private sectors and academia, all of whom contribute their expertise in the public interest. The program is supported by state transportation departments, federal agencies including the component administrations of the U.S. Department of Transportation, and other organizations and individuals interested in the development of transportation. www.TRB.org 
TRANSPORTATION RESEARCH BOARD

500 Fifth Street, NW

Washington, DC 20001

\section{THE NATIONAL ACADEMIES}

Advisers to the Nution on Science, Engineering, and Medicine

The nation turns to the National Academies - National Academy of Sciences. National Academy of Engineering, Institute of Medicine, and National Research Councilfor independent, objective advice on issues that affect people's lives worldwide.

mww.national-academies.org 